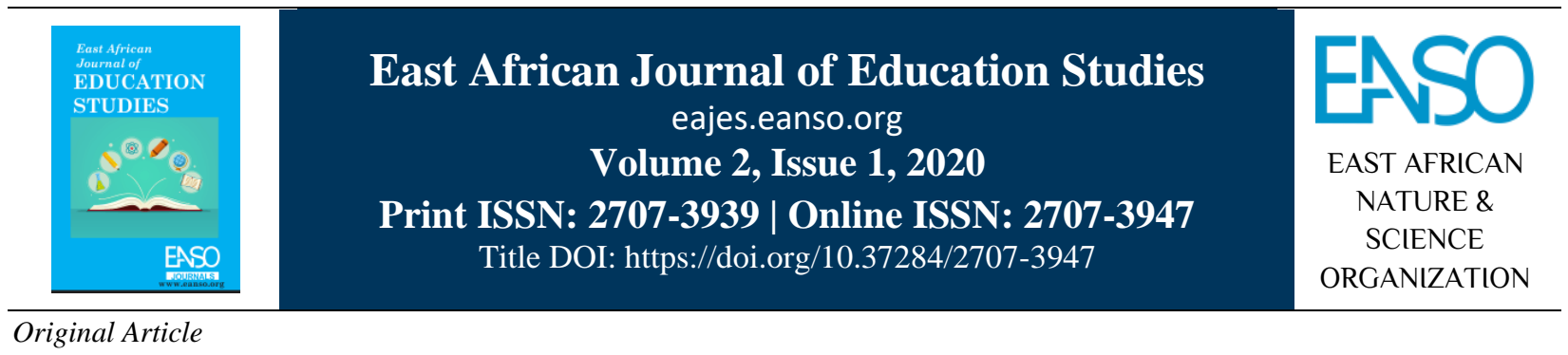

\title{
Distance Learning During COVID-19 Crisis: Primary and Secondary School Parents Experiences in Kenya
}

\author{
Sr. Mary Theodorah Mabeya, $P h D^{1^{*}}$ \\ ${ }^{1}$ School of Education, Catholic University of Eastern Africa, P. O. Box 908 - 30100, Eldoret, Kenya. \\ * ORCID: http://orcid.org/0000-0001-7297-9797; Correspondence Email: sistermarymabeya@ gmail.com.
}

Article DOI: https://doi.org/10.37284/eajes.2.1.249

\section{Date Published: ABSTRACT}

12 December 2020 The COVID-19 disease outbreak in 2020 was declared by the World Health Organization as a Public Health Emergency (PHEIC). Human symptoms of the

Keywords: Coronaviruses among others are commonly spread through droplets (coughing)

Remote Learning, and close personal unprotected contact with an infected person through Distance Learning,

Digital Learning, COVID-19,

Secondary Schools, Coronavirus. toughing. Based on the speed at which the disease spreads, learning institutions were distinguished as high-risk areas with prospective of exposing both learners and instructors the spreading the virus. This had a serious effect on the academic programs in all learning institutions worldwide where learning was abruptly discontinued and all students and instructors send home. The Government of Kenya (GOK) through the President's directives suspended all learning institutions as one of the measures taken by the Ministry of Health to mitigate the spread of COVID-19. This affected the learning since most of the schools had not even started their syllabus that academic year. Alternative measures to ensure that curriculum implementation progressed well; various mechanisms were suggested including remote learning which was actualised in some instances. Virtual lessons and Open and Distance e-learning (ODeL) has mainly been adopted by institutions of higher learning (colleges and universities) globally in offering online classes. However, this was not the case in many public primary and secondary institutions where the common form of learning involves a very interactive physical relationship between teachers and their learners in classrooms. In Kenya, since all institutions of learning were closed as a result of the breakout of the COVID-19 pandemic, the Ministry of Education (MOE) opted for remote learning across the country. Research results from Rangwe Sub-county have shown that most learners have not benefited much from the online classes due to the network and other related challenges reported in this paper. This has created education inequity since 
parents who have children in private schools and those from well of backgrounds are the ones enjoying distance learning programmes offered. The research has also found out that parents did no proper supervision to ensure that their children were committed in their studies in remote settings. Lack of supportive infrastructure (electricity and internet network access) limited children participation in distance learning programmes in Rangwe Sub-county. The paper recommends that government to properly educate parents, teachers and learners on modalities of distance and remote learning programmes. There is need for government to provide children from disadvantaged families with technological appliances to enable them to participate in distance education.

\section{APA CITATION}

Mabeya, M. T. (2020). Distance Learning During COVID-19 Crisis: Primary and Secondary School Parents Experiences in Kenya. East African Journal of Education Studies, 2(1), 173-186. https://doi.org/10.37284/eajes.2.1.249.

\section{CHICAGO CITATION}

Mabeya, Mary Theodorah. 2020. "Distance Learning During COVID-19 Crisis: Primary and Secondary School Parents Experiences in Kenya”. East African Journal of Education Studies 2 (1), 173-186. https://doi.org/10.37284/eajes.2.1.249.

\section{HARVARD CITATION}

Mabeya, M. T. (2020) "Distance Learning During COVID-19 Crisis: Primary and Secondary School Parents Experiences in Kenya”, East African Journal of Education Studies, 2(1), pp. 173-186. doi: 10.37284/eajes.2.1.249.

\section{IEEE CITATION}

M. T. Mabeya, "Distance Learning During COVID-19 Crisis: Primary and Secondary School Parents Experiences in Kenya", EAJES, vol. 2, no. 1, pp. 173-186, Dec. 2020.

\section{MLA CITATION}

Mabeya, Mary Theodorah. "Distance Learning During COVID-19 Crisis: Primary and Secondary School Parents Experiences in Kenya”. East African Journal of Education Studies, Vol. 2, no. 1, Dec. 2020, pp. 173-186, doi:10.37284/eajes.2.1.249.

\section{INTRODUCTION}

Majority of countries across the world have prioritised basic education as a right that every child should enjoy. According to the World Bank (2018) report, education is a human right and a powerful force for a country's economic and social development. The momentous of access to education is further reflected in the Millennium Goals (MDGs) commitment that all children must attain a course in Basic Education (UN, 2011). The commitments made by various governments toward ensuring universal primary education goals are attained with an emphasis of no child left behind, queries the quality of education provided in schools through the precondition of adequate acquiescent infrastructure and instructional resources in both primary and secondary schools. The receipt of good quality education is one of the most important factors that enable children to fulfil their potential later in life and reduce poverty (Mabeya, Gikuhi \& Anyona, 2019). According to Daniel (2020), over the last 30 years, a huge worldwide development in the provision of quality education at all levels, have been emphasised. However, this attainment of the educational goals and provision of quality education has been halted by the emergence of a deadly disease in the name of COVID-19 across the world that has affected the education sector to the highest degree. For instance, United Nations Educational, Scientific and Cultural Organisation (2020) reported that more than 1 billion instructors and 575 million learners around the world had been affected by the closure of all basic learning institutions including universities as a preventive measure to maintain the spread of COVID-19 pandemic in most countries.

In Kenya, the first case of COVID-19 was confirmed on March 13, 2020 and the cases steadily rose and spread across the country. In order to adhere to the international and national guidance for social distancing, quarantine and self-isolation, the government closed the country's learning 
institutions (pre-primary, primary, secondary, colleges and universities) on March 16, 2020, as one of the stringent measures taken by the Ministry of Health to mitigate the spread of COVID-19 pestilence. According to the Ministry of Education (MOE, 2020), the pandemic has disrupted learning for more than 18 million learners which pose a threat for the attainment of Sustainable Development Goal (SDG) No 4 on accesses to quality, equitable and inclusive education. In order to support the continuation of learning remotely, a three-pronged approach was developed which primarily meant to expand access to learning through online content by the use of various technology.

Ngure (2012) argues that in Kenya, the physical, human and financial resources invested in schools do not just depend on the number of years covered but on the development of knowledge and skills young people acquire in the learning process. Furthermore, the aspects of teachers' and learners' motivation are influenced by the interaction and relationship spent in an instruction session. According to Daniel (2020), the COVID-19 pandemic in Kenya has a significant challenge on the quality of education across the counties where learners from low-income households and urban slums are most affected. This is because these are vulnerable persons who depend on schools for meals and other basics like sanitary towels for girls that are given by the government. The Kenyan government's suspension of all instructive institutions as a strategy to curb the pandemic and a requirement to switch almost overnight to remote learning methods (online teaching and virtual education) faces significant challenges. This has affected learners as most schools had not even started their current syllabus, which means that these learners will have to repeat their respective classes come 2021.

Opondo and Boit (2017) observed that the kind of education where learners are separated from the instructional phase of their instructors has a serious effect on the learners' consumption of informative skills in their learning processes. Orodho, Waweru, Ndichu and Nithinguiri (2013) revealed that the challenges of accessibility and adequacy of learning environment do affect the learning and teaching processes as it provides experience, stimulate the senses, encourage the exchange of information and offer opportunities for preparation, application and transfer of skills which are essential for learning. However, the Organisation for Economic Cooperation and Development (OECD, 2020) argues that the idea of distance and remote learning is an implication that not all learning ought to take place in a physical classroom. Furthermore, UNESCO (2020b) indicated that both public and private learning institutions all over the world should have in place alternative methods for both students and teachers to continue with their normal interactions when physical school instruction is not possible so long as the working environment is safe for the learners.

The new remote and distance learning methods shift the supervision roles of learning away from teachers in school and assigns these great responsibilities to parents. Epstein (2001) describes parents as partners in the education of their children. This is because they share common objectives of desiring the development of the full potential of their children in education. Previous studies have shown that parents are a valuable resource in the learners' intellectual development because their home involvement has a significant positive influence on their learning academic progress in schools (Epstein \& Sheldon, 2006; Lee, 2018). This means therefore that even with the shift in the mode of curriculum instruction in schools, parents play a critical role to ensure that remote, online and distance-learning approaches are successful and ensuring learners can acquire the competencies needed. The activities that parents can be engaged in aiding their children learn while at home may include helping with assignments, reinforcing fundamental concepts, continuing school-related discussions and encouraging them to pertain themselves to their school's prospectus (Lee, 2018). From this perspective, the remote and distance education technology rolled out should guide parents on their roles to ensure that the objectives of the learning continuity are met.

However, some observations made by interested stakeholders in education have received mixed reactions in regard to the significance of parents' involvement in the supervision of their children's learning processes. Human Rights Watch (2020) observed that the ongoing online program had 
increased inequity among learners, as the majority of the learners have no access to digital platforms due to lack of internet connectivity at home, different levels of parental academic qualifications and attitudes given that most children only respect their teachers. Olmstead (2013) and Altschul (2011) reported serious challenges encountered by parents in the process of taking part in school programmes as the use of technological platforms and interpretation of the curriculum raises issues. According to Kenya Institute of Curriculum Development (2018), the competency Based Curriculum (CBC) launched in January 2019 in Kenya, seeks to develop the learners 'ability in the application of appropriate skills and knowledge to successfully perform a function. According to him, the curriculum is significant to the application to the present situation as its objectives are based on the learner-centred approach, and the teacher's role is defined as only to facilitate the processes includes parental participation through being empowered and allowed to share the responsibility of their children in all ties and levels of basic education.

Schools play a significant role in the protection of learners, especially girls from vulnerable and marginalised communities where most parents are illiterate in areas of ICT literacy and accessibility of the devices is difficult to obtain. Lee (2018) indicated that at times, the underutilisation of educational technology results in unsatisfactory completion of assignments and important undelivered school notices to parents in the United States. Hatzigianni and Margetts (2014) attribute the challenges of new online learning approach and the underlying issues that contribute to parents' reluctance in the use of remote learning platforms should be addressed to ensure that students benefit from these platforms if the current closure of schools continues. It is therefore important to get what perceptions parents have towards remote distance and open learning and factors that contribute to their involvement, and preference with regard to the new form of learning to the benefit of their children in schools.

Despite the challenges perceived in the implementation of online learning approach, several benefits have been established in the shift from research conducted in different parts of the world. Among which stands out the chance for rapid progress in the area of digital learning which in other circumstances would take years (UNESCO, 2020b). The shift to remote learning approach has also been accessed as a significant opportunity for teachers and students to become flexible, aggressive, more creative, and innovative (Duraku \& Hoxha, 2020). Nevertheless, Alam and Tiwari (2020) noted that the success of remote learning has proven to be influenced by the way instructions are provided and their level of clarity, by the accessibility and suitability of technological equipment, by time, by motivation, and by support for participation in online learning including parents who are key stakeholders. Therefore, this paper focuses on the experiences that parents have towards the distance learning during this time of COVID-19 catastrophe in Kenya with specific reference to Rangwe Sub-county in Homa Bay County, Kenya.

\section{Statement of the Problem}

Parents perform a significant role in their children's basic education (Epstein, 2001); therefore, it is important that parents actively engage in their children's learning process during COVID-19 crisis. Research conducted in the past has shown that parents have been reluctant to support online learning (Lee, 2018) in developed countries leading to underperformance of their children in academics. Machado-Casas, Sanchez, and Ek (2014) noted that remote learning using technology had experienced a high degree of failure when it was measured by parental involvement. Parents' inability to embrace technological change in their children's academic and learning can have an adverse effect on children's school performance (Lee, 2018).

The Kenyan government closed educational institutions because of COVID-19 pandemic. In to the closures of schools, in May, the government of Kenya released Kenya Basic Education COVID-19 Emergency Response Plan (the Republic of Kenya, 2020) to recommended increased access to online teaching and learning materials through remote and distance learning programmes. One aspect of the directive was to ensure that the personnel involved are skilled for supporting education for all learners during current and future outbreaks. This means parents had to receive appropriate support to ensure that remote learning progresses well. The mode of 
delivering the curriculum content for primary and secondary schools was through uninterrupted radio and TV lessons covering the whole country. However, despite rolling out of distance and remote lessons through $\mathrm{TV}$, radio and online platforms, the experiences of parents who are key monitors and supporters of this programme remain un-researched even in the period when the pandemic was not there. It is due to the above reason that this paper investigates the perceptions of parents in Rangwe Sub-county, Homa Bay County on the implementation of remote learning and competencies acquisition by their children in Kenya. The objectives of the paper were to determine the medium for accessing distance learning in Rangwe Sub-county; to establish parents' views on distance learning in Rangwe subcounty and to find out the apprehension of parents and learners with regard to distance learning programmes in Rangwe Sub-county.

\section{Theoretical Framework}

The framework pivotal to this study research was Davis et al. (1989) Technology Acceptance Model (TAM). This study involved an attempt to explore parents' perceptions about the implementation of remote and distance learning by the Ministry of Education concerning their learners' continuation in learning during COVID-19 pandemic in Kenya. According to the TAM, the degree to which an individual uses technology has a direct link to that individual's acceptance of technology (Davis, 1989). Therefore, parents' decision to use the implemented remote learning technology will have a direct effect on their children academic growth. Using the TAM, Davis et al. contended that an individual's decisions regarding technology use hinge on factors such as perceived usefulness, perceived ease of use, attitude, and behavioural intentions. Fan and Yan contended that any of these factors could produce a negative response to the acceptance of the technology. The TAM framework has been applied to generate some insights into reasons parents made decisions on whether to participate or note in remote learning platforms initiated at their children's school. This is the reason that the researcher decided to use this TAM theory to establish the perceptions that parents have towards remote learning in Homa Bay County, Kenya.

\section{LITERATURE REVIEW}

A child's success in education in most occasions depends on the level of support received from the parents. Parental support has a significant impact on a child's academic accomplishment and intellectual health. Students who have parents that take significant attention in their education are more likely to earn higher grades, take more challenging courses, increase their opportunities of passing academic courses, attend school regularly, have better social skills, graduate, and attend postsecondary education (Epstein \& Sheldon, 2006). Parental involvement in children's education initiates the learning processes before the child begins school (Keaton, 2017). Daniel (2020) observed that COVID-19 virulent disease is a huge challenge to education systems globally. Nyerere, Gravenir, and Mse (2012) also observed that the increased demand and need for continuity in learning have led to the introduction of open, distance, and e-learning (ODeL) in many countries. The stipulation of this mode of learning has, however, been faced with a variety of confrontations, among them infrastructural challenges.

\section{Empirical Studies}

In the United States, Smith, Burdette, Cheatham and Harvey (2016) investigated parents' perceptions and experiences regarding completely online learning for their children with disabilities. Transcribed interviews were examined to inductively construct themes across all participants' interviews using a constant comparative method. Three researchers independently reviewed a single transcript (i.e., three of 19 transcripts) to identify initial themes. Next, the researchers met and developed consensus themes for analysing the remaining transcripts. Results suggest that with the growth in $\mathrm{K}-12$ fully online learning experiences, the parent (or adult member) in students' households takes on added responsibilities for the child with disabilities to participate in schooling. In particular, parents take on the role of teacher. Based on this new teachers' role come to a greater need for increased parent-teacher communication regarding their children's learning as well as greater parent time commitments. Besides, parents discussed several barriers to their ability to 
participate in their children's completely online learning experience.

Lee (2018) study described the meaning of human experiences as they related to parents' reluctance in using learning management systems (LMSs). Elements from Rogers's innovation diffusion theory, Davis's technology acceptance model, and Epstein's parent involvement model were combined for the study's conceptual framework. Six parent participants from a small suburban school district in the South-eastern United States who self-disclosed that they used LMS less than 3 times per week and had a child that scored at the beginning level of the mandatory state test were purposefully selected for this study. The findings indicated that parents avoided using LMSs for several reasons, which included parents' lack of knowledge regarding accessing and using LMSs, ineffective orientation practices, lack of technical support, and lack of support for training.

Keaton (2017) looked at teachers' perceptions of the efficacy of parents and community outreach strategies based on Epstein et al.'s (2001) six types of involvement. The population of teachers selected to participate in the study survey were from three elementary schools, six middle-level schools, and ten high-level schools. The results from the survey indicated that all the 24 examples were perceived to be effective by teachers. Data from the interview concluded that although the examples of strategies were effective, teachers lacked time to implement them all. Based on the information from the interviews, teachers should implement strategies that would be the most successful for the parent and student population at a particular school. Borup, Graham and Davies (2013) examined parental involvement in an online learning environment. Using survey data, found that students and parents largely viewed parent-instructor and learner-parent interactions as motivational. Students viewed learner-parent interaction to be significantly more motivational than did their parents. The quantity of reported parental interactions was largely negatively correlated with course outcomes. These negative correlations may be the result of parents' tendency to increase interaction levels following poor student performance and may not reflect the actual impact of parental interactions on student learning at the individual level.
In Kosovo, Duraku and Hoxha (2020) explored the concerns of students, parents, and teachers related to the circumstances caused due to social isolation, and the perspectives of teachers and parents concerning remote or online learning. This study adopted the qualitative research design. In the framework of this study, the case study research strategy was used. According to the findings of this study, the new circumstances created due to the spread of COVID-19, including changes in education, have caused a number of concerns among students, parents, and teachers in Kosovo. The findings from the study confirm the common concerns of the two reporting groups in the study in relation to student assessment, worries and overload, as well as evaluations of the incompatibility of the learning conducted so far. The findings of this study confirm the readiness and motivation of teachers to advance their knowledge and skills, as well as to contribute to advance the quality of education. In the United Arab Emirates, Abdallah (2018) investigated parents' understanding and perception of supporting, encouraging and adopting e-learning initiatives, Primary and secondary data sources were used. The results showed that parents' satisfaction was moderate with teacher computer competence, whereas they are highly satisfied with student computer competence. The students' personal development, meeting students' needs through the curriculum, quality teaching and learning all these domains showed parents low satisfaction as per the results. Results showed as well e-learning can improve the quality of students learning according to parents' perception through providing them with a wide variety of accessibility of learning materials.

Meier and Lemmer (2015) examined parents' perceptions of their child's schooling, gathered by means of an annual questionnaire administered in a public primary school in Gauteng, South Africa. A researcher-designed questionnaire administered annually over two consecutive years (2012 and 2013) was used to gauge parents' opinions of school culture, home-school communication, classroom instruction and classroom organisation. The results indicate that parents were generally satisfied with all four areas. However, parents indicated concerns about reporting on an individual learner's progress, academic achievement, and social and emotional well-being, as well as 
academic enrichment opportunities, and ways for parents to assist learning at home. Mukama (2018) analysed the interplay between policy formulation and implementation in terms of the historical practices of open distance learning (ODL) in Rwanda. This study analysed discourses emerging from policy statements on ODL and scrutinised how government aspirations were translated into concrete actions. Moreover, the study examined the rationality governing ODL practice and explored governing techniques adopted in relation to ODL discourses. The findings reveal that, though policies extol ODL potential to increase access, relevance and inclusion in education, and though they highlight the need to improve quality in higher education through affordable, scalable and sustainable technologies, implementing institutions tend to adopt contentious approaches to cope with a dual-mode.

Nyerere, Gravenir and Mse (2012) conducted a survey study in two public universities offering virtual classes mechanisms of ODeL, the University of Nairobi and Kenyatta University. These universities were purposely selected for the study, whose respondents included students who had registered in ODeL system, the lecturers and senior administrators involved in the program. Analysis of relevant documents was carried out, while library systems were reviewed on the amalgamation of ODeL in the provision of quality education in Kenya. The study established that resourceful and optimal delivery of ODeL in the education system has several impediments both economic and infrastructural challenges. However, the reinforcements of the existing relevant structures would be significant in addressing some of the challenges. Mutisya and Makokha (2016) in their study established that challenges affecting the adoption of e-learning in these institutions of higher learning. Data was collected using questionnaires administered to 420 lecturers and 210 students and analysed through the use of simple descriptive statistics. Lecturers ranked heavy workloads the most serious challenge affecting the adoption of elearning, followed by insufficient Internet connectivity, denial of copyrights for their developed e-learning modules, limited information and communication technology (ICT) skills, lack of incentives, shortage of computers/laptops, inadequate computer laboratories, and insufficient time for online interaction. Students, on the other hand, ranked insufficient Internet connectivity the number one challenge, followed by a lack of computers/laptops, inadequate computer laboratories, limited ICT skills, and insufficient time for online interaction. Tarus, Gichoya and Muumbo (2015) findings from a survey of 148 staff of three Kenyan public universities who are currently using e-learning in blended mode approach. Data was collected through questionnaires, in-depth interviews and document analysis. The findings reveal that e-learning comes with some challenges that must be addressed by Kenyan public universities before successful implementation can be realised. However, the benefits and opportunities presented by e-learning far outweigh the challenges. The paper finally recommends some possible solutions that public universities could embrace towards successful implementation of e-learning.

\section{MATERIALS AND METHODS}

Mixed method research was the methodology that was utilised in this research as it incorporated qualitative and quantitative techniques. The study was conducted in Rangwe Sub-county, Homa Bay County by selecting parents of children in primary and secondary schools as respondents for the study. Due to COVID-19 restrictions, the study selected 30 parents to be involved in this investigation. The instrument used to collect data was a questionnaire which was structured according to the objectives of the paper and contained open-and close-ended questions. The parents were selected using a convenience sampling technique. Analysis of data has been done using qualitative and quantitative forms and presented in tables, graphs and text in the next sub-section.

\section{RESULTS AND DISCUSSIONS}

The study collected information from parents about their various social-economic activities. The results are presented in Table 1 . 
East African Journal of Education Studies, Volume 2, Issue 1, 2020

Article DOI: https://doi.org/10.37284/eajes.2.1.249

Table 1: Demographic Information of Parents

\begin{tabular}{llll}
\hline Variable & Category & Frequency & Percent \\
\hline Gender & Male & 19 & 65.5 \\
& Female & 10 & 34.5 \\
& Total & $\mathbf{2 9}$ & $\mathbf{1 0 0 . 0}$ \\
\hline Age bracket & 24 years and below & 6 & 20.7 \\
& 25-34 years & 4 & 13.8 \\
& 36-44 years & 7 & 24.1 \\
& 45-54 years & 3 & 10.3 \\
& 56 years and above & 9 & 31.0 \\
& Total & $\mathbf{2 9}$ & $\mathbf{1 0 0 . 0}$ \\
\hline Education & No formal education & 4 & 13.8 \\
& Primary & 9 & 31.0 \\
& Secondary & 8 & 27.6 \\
& Tertiary & 8 & 27.6 \\
& Total & $\mathbf{2 9}$ & $\mathbf{1 0 0 . 0}$ \\
\hline Source of income & Employment & 5 & 17.2 \\
& (government) & & \\
& Employment (private) & 7 & 24.1 \\
& Self-employment & 4 & 13.8 \\
& (business) & & \\
& Farming & 12 & 41.4 \\
& No employment & 1 & 3.4 \\
& Total & $\mathbf{2 9}$ & $\mathbf{1 0 0 . 0}$ \\
\hline
\end{tabular}

Demographic information result shows that in terms of gender participation, $19(65.5 \%)$ were male and $10(34.5 \%)$ were females. On the age bracket, $6(20.7 \%)$ were aged 24 years and below, $4(13.8 \%)$ were aged $25-34$ years, $7(24.1 \%)$ were aged 36-44 years, $3(10.3 \%)$ were aged $45-54$ years, and $9(31.0 \%)$ were aged 56 years and above. In terms of education level, $4(13.8 \%)$ of parents had no formal education, $9(31.0 \%)$ had primary level of education, $8(27.6 \%)$ had secondary level of education, and $8(27.6 \%)$ had tertiary level of education consisting of certificates, diploma and degrees. On the household source of income, 5
(17.2\%) were employed by the government, 7 $(24.1 \%)$ were employed by the private sector, 4 $(13.8 \%)$ were engaged in business, $12(41.4 \%)$ participated in various farming activities (livestock keeping, crop farming and fishing) whereas 1 (3.4\%) was not employed nor engaged in any economical venture.

Further, from these parents, they were asked to provide the number of their children who were in primary, secondary and tertiary level. The descriptive outcomes are given in Table 2.

Table 2: Distribution of Parents Children across Various Levels of Education

\begin{tabular}{llll}
\hline Level of schooling & Parents $(\mathbf{N})$ & $\begin{array}{l}\text { No. of children } \\
\text { Min }\end{array}$ & Max \\
\hline Primary school & 29 & 1.00 & 4.00 \\
Secondary school & 13 & 1.00 & 3.00 \\
Tertiary (colleges \& universities & 12 & 1.00 & 1.00 \\
Valid N (listwise) & & 1 & 3 \\
\hline
\end{tabular}

All of the parents (29) indicated that they had children in primary schools; 13 parents had children in secondary schools, while 12 had children in colleges and universities. Many parents from 
Rangwe Sub-county had children in public primary schools $(22,75.9 \%), 4(13.8 \%)$ had children enrolled in private primary schools whereas 3 (10.3\%) had children enrolled in both private and public. The representation of these different categories of schools is significant to understand how distance learning programme is being felt by parents in the time of COVID-19crisis. The parents were asked to provide their experience with the new distance learning programme that the government had launched in May 2020. Out of the 29 parents, $20(69.0 \%)$ did not answer to this query, $2(6.9 \%)$ said that the programme is not functioning because children cannot get the programme, 4 (13.8\%) indicated the programme to be expensive while 3 $(10.3 \%)$ called for more preparations and research to ensure the programme succeeds. Nevertheless, the researcher went ahead to ask them which channel was appropriate for their children to access distance learning content programmes for primary and secondary school children. The responses are provided in Table 3.

Table 3: Medium for Accessing Distance Learning Programmes by Children in Rangwe Sub-county

\begin{tabular}{|c|c|c|}
\hline $\begin{array}{l}\text { Medium for } \\
\text { accessing }\end{array}$ & Frequency & Percent \\
\hline None & 2 & 6.9 \\
\hline TV & 4 & 13.8 \\
\hline Radio & 15 & 51.7 \\
\hline Phone & 2 & 6.9 \\
\hline Tablet & 2 & 6.9 \\
\hline TV and Radio & 2 & 6.9 \\
\hline TV and computer & 2 & 6.9 \\
\hline Total & 29 & 100.0 \\
\hline
\end{tabular}

The result shows that half $15(51.7 \%)$ of children in Rangwe Sub-county only accessed the distance learning programmes through radio, 4 (13.8\%) accessed through Television, 2 (6.9\%) through mobile phones and 2 (6.9\%) through tablets. However, $2(6.9 \%)$ of parents admitted that their children could not access distance learning programmes as they did not have an appropriate medium to enable them to participate in such programmes. This means that the majority of children in Rangwe Sub-county only rely on battery-powered radios to access distance learning programmers in times of COVID-19 pandemic.
Further, the parents were asked to indicate the period of time through which their children participated in the distance learning programmes. The results are presented in Table 4.

Table 4: Time When Children Participate in Distance Learning

\begin{tabular}{lll}
\hline Period & Frequency & Percent \\
\hline During the evening & 8 & 27.6 \\
$\begin{array}{l}\text { Morning hours } \\
\text { Throughout the day }\end{array}$ & 8 & 27.6 \\
$\begin{array}{l}\text { No engagement but } \\
\text { learning on their own }\end{array}$ & 2 & 31.0 \\
$\begin{array}{l}\text { Weekends and morning } \\
\text { hours daily }\end{array}$ & 2 & 6.9 \\
Total & $\mathbf{2 9}$ & 6.9 \\
\hline
\end{tabular}

Results show that $9(31.0 \%)$ of parents indicated that there was no specific time in the day that their children participated in distance learning because the lessons being broadcasted are done at different times by different media channels. Other $8(27.6 \%)$ said their children are engaged in distance learning during the evening, $8(27.6 \%)$ said distance learning happens during morning hours with 2 $(6.9 \%)$ indicating that their children had no specific learning time because they did not have access to media channels to enable them to participate in remote learning. The result shows that the participation of children in distance learning programmes varies in times of the day.

During the period of COVID-19 pandemic occasioned by school closures; parents are expected to offer required support to their children to enable them to continue learning. Therefore, the parents were asked to indicate if they were providing necessary instructional materials required for remote learning programme for their children. Most $21(72.4 \%)$ of parents noted that they were not in a position to provide required instructional learning materials for their children during the period of distance learning in Rangwe Sub-county and only 8 $(27.6 \%)$ were able to provide. For those who indicated that they had not provided, they indicated that due to COVID-19 pandemic and partial lockdown, they had to fend for their children food first before thinking about purchasing extra learning materials. For those who were able to purchase some instructional materials to support 
their children learning, they indicated that they purchased past examination papers to keep their children busy while others downloaded learning materials from school WhatsApp groups (those from private schools) which they printed and provided to their children. This means that majority of parents in Rangwe Sub-county were unable to purchase necessary instructional materials to enable their children to participate fully in distance learning programme during COVID-19 pandemic period.

During the COVID-19 pandemic, schools were closed and teachers were separated with their learners, and therefore the government requested the parents to work with their children. Because most parents are not trained in instructional activities, the researcher asked to indicate whether there existed any communication between them and their children teachers during distance learning programmes. Most 19 (65.5\%) have never communicated with teachers of their children on their children learning programmes remotely, 4 $(13.8 \%)$ were the ones who maintained frequent communication while $6(20.7 \%)$ admitted that they sometimes communicated with their teachers. Those parents who appeared to communicate regularly with their children teachers were mainly from schools that were offering Zoom and Google Meeting classes unlike the majority of parents from public primary schools whose lesson delivery was through radios.

Further, the research to know the specific roles that parent in Rangwe Sub-county played to ensure continuity of learning for their children during the period of COVID-19 pandemic. Results are presented in Table 5.

Table 5: Parental roles in ensuring continuity of learning for their children

\begin{tabular}{lll}
\hline Roles & Frequency & Percent \\
\hline None & 2 & 6.9 \\
Encourage my children to study & 4 & 13.8 \\
Make sure they are available for the programme & 15 & 51.7 \\
Provide them with textbooks & 2 & 6.9 \\
Purchasing and downloading the required materials for learning & 3 & 10.3 \\
Release them from other household chores & 3 & 10.3 \\
Total & $\mathbf{2 9}$ & $\mathbf{1 0 0 . 0}$ \\
\hline
\end{tabular}

The result shows that half $15(51.7 \%)$ of parents said that they made arrangements to ensure that their children were prepared for remote learning classes, $4(13.8 \%)$ of parents encouraged their children to study, 3 (10.3\%) went ahead to purchase and download learning materials for their children, $3(10.3 \%)$ also released the children from performing household chores to attend distance learning lessons. In comparison, 2 (6.9\%) went to bookshops to purchase various story and textbooks for their children. The result shows that despite many parents being unable to provide required instructional support, they went an extra mile to ensure that their children were supported with whatever they had to continue with their education.
The parents were asked to indicate if they were provided with the guideline by the government and their schools on how to evaluate their children distance learning programmes. The result shows that only $7(24.1 \%)$ of parents admitted to being provided with evaluation guidelines for remote learning programmers, whereas majority 22 $(75.9 \%)$ were not provided with. This means that as the government and schools are implementing remote learning programmes, the parents have not been provided with tools and methods of assessing their learners. This led to the question that the researcher asked parents to indicate how they were assessing their children irrespective they had the guideline or not. The results are presented in Table 6. 
East African Journal of Education Studies, Volume 2, Issue 1, 2020

Article DOI: https://doi.org/10.37284/eajes.2.1.249

Table 6: Methods of parents assessing their children

\begin{tabular}{lll}
\hline Methods & Frequency & Percent \\
\hline Not able to assess & 16 & 55.2 \\
$\begin{array}{l}\text { Very little content consumption as no serious follow up is given - learners not } \\
\text { interested }\end{array}$ & 10 & 34.5 \\
$\begin{array}{l}\text { Repeated assessment is required to ensure the child acquires the knowledge } \\
\text { Total }\end{array}$ & 3 & 10.3 \\
\hline
\end{tabular}

The result shows that most parents (55.2\%) did not have the methods of assessing their learners' distance learning programs while those who admitted one method, they conducted repeated assessment while others indicated that their children were not serious with what they were assessing them hence affecting their understanding of the subject matter being taught. Thus far, the study asked the parents to provide information on the challenges that they encounter in the implementation of distance learning programmers in their homes. The results are presented in Table 7.

Table 7: Challenges encountered by parents in the implementation of distance learning programmes

\begin{tabular}{lll}
\hline Challenges & Frequency & Percent \\
\hline Not practical in remote areas with no electricity & 6 & 20.7 \\
Cost of purchasing and learning is high & 6 & 20.7 \\
$\begin{array}{l}\text { Difficult to supervise them since I have never been a teacher and don't } \\
\text { understand needed content or syllabus to follow }\end{array}$ & 4 & 13.8 \\
Children cannot listen to their parents as teachers & & \\
Strictness during supervision & 24.1 \\
They lose interest after a short while and run out & 2 & 6.9 \\
Programmes not modified to suit the needs of disabled children & 2 & 6.9 \\
Total & $\mathbf{2 9}$ & 6.9 \\
\hline
\end{tabular}

Results show that the main challenge that most parents in Rangwe Sub-county faced was due to lack of supportive infrastructure (electricity and internet connections) making it impossible for parents in remote areas to facilitate their children learning through various media platforms. Another challenge that was mentioned related to cost of appliances (TVs, laptops, modems, tables) to enable their children access remote learning effectively which was not possible by many parents owing to the COVID-19 pandemic and high poverty level. Another challenge that was reported is that some children did not take seriously what their parents were instructing them, considering they were not in a school environment. It can also be seen that the difficult to supervise children remotely was also a challenge as parents were concentrating on fending for them. This made the researcher ask parents to propose various strategies that could be done to ensure that their children from Rangwe enjoy similar privileges of participating in distance education with children from urban areas. Their responses are provided in Table 8.

\section{Table 8: Suggestions on Improvement of Distance Learning}

\begin{tabular}{lll}
\hline Suggestions & Frequency & Percent \\
\hline Electricity connection & 6 & 20.7 \\
Provide a portal for all learners and train teachers on how to reach their & 4 & 13.8 \\
learners on time & & 6.9 \\
Ensure all children can access TV if possible or get them tables & 2 & 6.9 \\
Create awareness on how the programme is evaluated & 2 & 6.9 \\
To ensure the network is not interrupted frequently & 2 & \\
\hline
\end{tabular}




\begin{tabular}{lll}
\hline Suggestions & Frequency & Percent \\
\hline Govt to provide assistive devices to enable special needs learners to learn in a & 2 & 6.9 \\
remote method & & \\
Work with the local administration to delivery hard copy materials & 3 & 10.3 \\
Create awareness on both learners, teachers and parents & 8 & 27.6 \\
Total & $\mathbf{2 9}$ & $\mathbf{1 0 0 . 0}$ \\
\hline
\end{tabular}

Results show that many parents believed that there is a need for parents, teachers, and learners to be empowered on distance learning programmes by the government. This will enable them to enjoy the benefits(s), which are many that the programme provides. Further, the parents indicated that there was a need for the government to roll out electricity and internet connection to all remote areas to ensure learners benefit, among other recommendations provide there above.

\section{CONCLUSIONS AND RECOMMENDATIONS}

This paper investigated the experiences of parents with children in primary and secondary schools on the distance learning program offered by government and schools across Kenya. Results showed that the majority of children in Rangwe Sub-county accessed distance learning programmes through radio. However, the frequency to which the children accessed the remote learning programmers was irregular as their parents were unable to supervise or keep watch on them. The result showed that most parents complained that they were unable to offer required instructional and assessment support to their learners to enable them to continues with their education. Moreover, despite government and institutions rolling out the programmes, it was discovered that there was no guideline provided to the government on how they were going to support their children learn apart from parents whose children were in private schools. This means that parents had different perceptions of the effectiveness of the distance learning programme to ensure continuity in learning for their children. The lack of provision of required instructional materials was compounded by the effects of COVID-19 and also lack of necessary infrastructure (electricity and internet) to ensure that remote learning succeeded during the period of school closures. With this in mind, the research makes the following recommendations: (a) There is a need for the government to empower and create awareness to parents, learners and teachers on the modalities of distance education to ensure its benefits are attained by schools.

(b) To ensure there is the success of the programme during the post-COVID-19 period, there is a need for the government to ensure that there are electricity and internet access to rural and urban areas of the country. This will bring equity since children from remote regions will benefit from those from developed areas.

(c) One of the problems identified was the cost of appliances to support distance learning; there is a need for the government to ensure the provision of e-learning resources to all learners in primary and secondary schools. If that is not possible, there is a need for the government to zero-rate all technology appliances to make them affordable to many families.

\section{REFERENCES}

Abdallah, A. K. (2018). Parents perception of elearning in Abu Dhabi schools in the United Arab Emirates. International E-Journal of Advances in Social Sciences, 4(10), 30-41.

Alam, A. \& Tiwari, P. (2020). Putting the 'leaning' back in remote learning: Policies to uphold effective continuity of learning through COVID19. Issue Brief, UNICEF Office of Global Insight and Policy.

Altschul, I. (2011). Parental Involvement and the Academic Achievement of Mexican American Youths: What Kinds of Involvement in Youths' Education Matter Most? Social Work Research, 35(3), 159-170, 
Borup, J., Graham, C. R., \& Davies, R. S. (2013). The nature of parental interactions in an online charter school. American Journal of Distance Education, 27(1), 40-55.

Daniel, S. J. (2020). Education and the COVID-19 pandemic. Prospects, 1-6.

Davis, F.D., Bagozzi, R. \& Warshaw, P.R. (1989). User Acceptance of Computer Technology: A Comparison of Two Theoretical Models. Management Science, 35(8), 982-1003DOI: 10.1287/mnsc.35.8.982

Duraku, Z. H. \& Hoxha, L. (2020). The impact of COVID-19 on education and on the well-being of teachers, parents, and students: Challenges related to remote (online) learning and opportunities for advancing the quality of education. Retrieved online from https://www.researchgate.net/publication/3412 97812

Epstein, J. L. (2001). School, family, and community partnerships: Preparing educators and improving schools. Boulder, Colorado: Westview Press.

Epstein, J. L., \& Sheldon, S. B. (2006). Moving forward: Ideas for research on school, family, and community partnerships. In C. F. Conrad \& R. Serlin (Eds.), SAGE handbook for research in education: Engaging ideas and enriching inquiry (pp.117-138). Thousand Oaks, CA: Sage Publications.

Hatzigianni, \& Margetts, K. (2014). Parents' beliefs and evaluations of young children's computer use. Australasian Journal of Early Childhood. https://doi.org/10.1177\%2F1836939114039004 15

Human Rights Watch (2020). Impact of Covid-19 on Children's Education in Africa: 35th Ordinary Session. Available at: https://www.hrw.org/news/2020/08/26/impactcovid-19-childrens-education-africa

Keaton, M. L. (2017). Teacher Perceptions of the Efficacy of Parent and Community Outreach Strategies. Doctorate Dissertation. CarsonNewman University.
Kenya Institute of Curriculum Development (2018). Report on competency based curriculum activities presented to the national steering committee. Nairobi: KICID.

Lee, M. L. (2018). Parents of At-Risk Students Reluctance to Using Technological Learning Platforms. Doctoral dissertation. Walden University.

Mabeya, M. T., Gikuhi, M. \& Anyona, N. J. (2019). Influence of working conditions on teacher attrition in public secondary schools in Uasin Gishu County, Kenya. European Journal of Education Studies, 6(5), 57-101.

Machado-Casas, M. Sanchez, P. \& Ek, L.D. (2014). The digital literacy practices of Latina/o immigrant parents in an after-school technology partnership. Multicultural Education, 21(3/4), 28-33.

Meier, C. \& Lemmer, E. (2015). What do parents really want? Parents' perceptions of their children's schooling. South African Journal of Education, 35(2), 1 - 11.

Ministry of Education (2020). COVID-19 guidelines. Available at https://www.education.go.ke/images/COVID19_GUIDELINES.pdf

Mukama, E. (2018). From policies to implementation of open distance learning in Rwanda: a genealogical and governmentality analysis. Journal of Learning and Development, $5(1), 40-5$.

Mutisya, D. N. \& Makokha, G. L. (2016). Challenges affecting adoption of e-learning in public universities in Kenya. E-Learning and Digital Media, 13(3-4), 140 - 157.

Ngure, S.M. (2012). Impact of resource utilisation as perceived by teachers in secondary schools in Mathioya District, Muranga County, Kenya. MBA Project, Kenyatta University. http://irlibrary.ku.ac.ke/handle/123456789/6463.

Nyerere, J. K. A., Gravenir, F. Q. \& Mse, G. S. (2012). Delivery of open, distance, and elearning in Kenya. International Review of 
Research in Open and Distance Learning, 13(3), 185-205.

OECD. (2020). Supporting the continuation of teaching and learning during the COVID-19 Pandemic Annotated resources for online learning. Paris: OECD.

Olmstead, C. (2013). Using Technology to Increase Parent Involvement in Schools. Techtrends Tech Trends, 57 , 28-37. https://doi.org/10.1007/s11528-013-0699-0.

Opondo, P. A. \& Boit, J.K. (2017). Challenges of Open and Distance Learning in Kenya: The Case of Public Universities. Proceedings of Kibabii University 2nd Interdisciplinary International Scientific Conference; June 14-15. Kibabii University.

Orodho, J.A., Waweru, P.N., Ndichu, M. \& Nthinguri, R. (2013). Basic education in Kenya: Focus on strategies applied to cope with schoolbased challenges inhibiting effective implementation of curriculum. International Journal of Education and Research, 1 (11), 120.

Rizun, M. \& Strzelecki, A. (2020). Students' Acceptance of the COVID-19 Impact on Shifting Higher Education to Distance Learning in Poland. International Journal of Environmental Research and Public Health, 17, -9; 6468; doi:10.3390/ijerph17186468

Smith, S. J., Burdette, P. J., Cheatham, G. A. \& Harvey, S. P. (2016). Parental role and support for online learning of students with disabilities: a paradigm shift. Journal of Special Education Leadership, 29(2), 101-112.

Tarus, J. K., Gichoya, D. \& Muumbo, A. (2015). Challenges of Implementing E-Learning in Kenya: A Case of Kenyan Public Universities. International Review of Research in Open and Distributed Learning, 16(1), 120-141.

UNESCO. (2020a). COVID-19 Impact on Education Data. COVID-19 Education Disruption and Response. Paris, France: United Nations Educational, Scientific and Cultural Organization.
UNESCO. (2020b, March 30). COVID-19 Webinar: A new world for teachers, education's frontline workers. Retrieved from https://en.unesco.org/news/COVID-19 webinar-new-worldteachers-educationsfrontline-workers

United Nations (2011). The millennium development goals; 2011 progress chart. www.un.org)(2011E)_MDReport2011_Progres sChart

World Bank (2018). World development report 2018: Learning to realise education's promise. Washington DC: World Bank Group. https://www.worldbank.org/en/publication/wdr 2018 